\title{
Novel Coronavirus (Covid-19) Knowledge, Attitude and Practice Amongst Dental Postgraduate Students to Prevent the Spread of Infection - A Cross Sectional Pan-India Survey Study
}

\author{
Rahul Suresh Jaiswal ${ }^{1}$, Hema Kanathila ${ }^{2}$, Anandkumar G. Patil ${ }^{3}$ \\ 1,2,3 Department of Prosthodontics, KAHER's KLE VK Institute of Dental Sciences, \\ Belagavi, Karnataka, India.
}

\section{ABSTRACT}

\section{BACKGROUND}

Healthcare worker's adherence to prevent the spread is related directly to their knowledge and attitude towards practices. Postgraduates (PG's) are expected to be at high risk of infection due to their exposure to saliva, blood, and aerosol / droplet production during dental procedures. We wanted to assess knowledge, attitude and practice of Indian dental postgraduate students to prevent the spread of novel coronavirus (Covid-19)

\section{METHODS}

The comprehensive cross-sectional survey questionnaire study was designed. The survey was conducted in the lockdown period (May 2020) among the Indian dental postgraduate students. A total of 1560 postgraduates made up the sample of study. The survey questionnaire was divided into four parts as demographic details, knowledge (9), attitude (7), and practice (5). The institutional ethical committee approved the study. The obtained data were transferred to the SPSS 13.01 program to draw the result.

\section{RESULTS}

Among the total participants ( $\mathrm{N}=1570), 64.81 \%$ were women, $20 \%$ of the total postgraduate students were not working in college. When the subjects were questioned regarding knowledge of Covid-19, female postgraduates compared to male, non working postgraduates, working postgraduate students of central zone and other zones showed higher knowledge. Also, while assessing the attitude and preventive measures taken by postgraduates, statistically significant difference was obtained irrespective of knowledge.

\section{CONCLUSIONS}

Dental postgraduate students did not have sufficient knowledge about the present critical situation. It is necessary that they should update their knowledge by pursuing educational courses regarding Covid-19 and by improving the standard of selfprotection.

\section{KEY WORDS}

Coronavirus 19, Dental Postgraduate, Knowledge, Attitude, Practice, Survey.
Corresponding Author: Dr. Rahul Jaiswal, Post Graduate Student, Department of Prosthodontics, KAHER's KLE VK Institute of Dental Sciences, Belagavi,

Karnataka, India.

E-mail: dr.jaiswal1993@gmail.com

DOI: $10.14260 / \mathrm{jemds} / 2021 / 445$

How to Cite This Article:

Jaiswal RS, Kanathila H, Patil AG. Novel coronavirus (Covid-19) knowledge, attitude and practice amongst dental postgraduate students to prevent the spread of infection a cross sectional pan - India survey study. J Evolution Med Dent Sci 2021;10(29):21762180, DOI: 10.14260/jemds/2021/445

Submission 15-03-2021,

Peer Review 19-05-2021,

Acceptance 26-05-2021,

Published 19-07-2021.

Copyright (C) 2021 Rahul Suresh Jaiswal et al. This is an open access article distributed under Creative Commons Attribution License [Attribution 4.0 International (CC BY 4.0)] 


\section{BACKGROUND}

Coronavirus disease 2019 abbreviated as "Covid-19" belongs to a family of single-stranded RNA viruses known as Coronaviridae and the disease was named Covid-19 by the World Health Organization (WHO). The coronavirus research group later renamed this pathogen as severe acute respiratory syndrome coronavirus 2 (SARS-CoV-2) ${ }^{1}$

In December 2019, novel coronavirus caused respiratory infection was first recognized in Wuhan, China. ${ }^{2}$ Person-toperson transmission through airborne droplets, feco-oral route, direct contact with an infected person or a contaminated surface is the mode of transmission of this deadly virus. It has an incubation interval of $2-14$ days. $^{3}$ The infected person usually presents with upper respiratory tract infection (URTI) and complains of high-grade fever, dry cough, and dyspnoea. ${ }^{4}$

The majority of countries in the world have noticed a substantial number of Covid-19 cases from December 2019 to January 30, 2020. Old age people with low immunity and medical problems, especially related to lungs, are more susceptible to Covid-19 disease. 5 The WHO had announced the rampant spread of SARS-CoV-2 and its related disease (Covid19) as a public health exigency with a currently known comprehensive mortality rate of $3.4 \% .^{6}$ The emergency committee has stated that the outspread of Covid-19 can be tackled by early recognition, segregation, implementation of a robust system to trace contacts and prompt treatment. ${ }^{7}$

Till date, no antiviral therapy or vaccine has been explicitly recommended for Covid-19. Therefore, taking preventive measures to control Covid-19 infection is the most critical intervention. ${ }^{8}$ Healthcare workers from the primary sector are constantly in contact with the patients in healthcare settings and hence dental healthcare professionals are expected to be at high risk of infection due to the exposure to saliva, blood, and aerosol / droplet production during the majority of the dental procedures. ${ }^{9}$ Therefore, SARS-CoV-2 dissemination during dental procedure may occur by aerosol / droplet ingestion from infected persons or direct contact with oral cavity, oral fluids, infected instruments and materials. Even though the risk of exposure is there in different areas of jobs, dental practitioners are facing the higher risk of coronavirus. ${ }^{10}$

Lessons learnt from the 2003 epidemic of extreme acute respiratory coronavirus syndrome indicate that awareness and behaviour towards infectious diseases are correlated with the degree of panic emotion and can further complicate the attempts to reduce the transmission of the disease. In order to promote Covid-19 epidemic control in India, there is an immediate need at this crucial moment to consider the consciousness of the dentist about Covid-19.

We wanted to assess knowledge, attitude and practice of Indian dental postgraduate students to prevent the spread of novel coronavirus 19.

\section{METHODS}

This cross-sectional questionnaire survey was conducted from May 7 to May 13 during the lockdown period in 2020. Since it was not suitable or practical to do a community-based national sampling survey throughout the course of this critical period, we decided to gather the data online. Relying on the author's network, a google form link was created and posted / reposted to the "WhatsApp" groups; the link was also posted on "Instagram", "Facebook" and "Twitter" account with the hashtag of Postgraduate dental students. This form contained a brief introduction to the focus and objectives of the survey. Informed consent was obtained from each participant before participation. Postgraduate students who were of Indian nationality, registered in any state dental council and who agreed to participate in the study were instructed to complete the questionnaire by clicking the link. Although the questionnaire was also distributed by the guiding staff, we did not constrict our sample to one state residents only. Residents of other states were also eligible for this survey if they were willing to participate. Confidentiality of the study participant's information was maintained throughout the study by making the participant's information anonymous and asking the participants to provide honest answers.

\section{Ethical Approval}

The Ethical Committee approved the study protocol and procedures before the formal survey. Participants had to answer a true - false question (Likert scale). After confirmation of the options, the participants were directed to submit the form.

The questionnaire was made up of two parts: First part was of demographic details, which had gender, health sector information, year of postgraduation, and regional information, and the second part had a questionnaire on knowledge of Covid-19, prevention of spread and attitude towards the treatment of patients. The questionnaire was developed after reviewing pertinent literature and was validated by doing a pilot study. The developed survey was then distributed to twenty randomly selected instructors to evaluate its readability and effectiveness. Refinements were made as needed to enhance interpretation and structure the questions before the final sample was circulated to the research population.

The questionnaire had nine questions on knowledge; (K1 K4) regarding clinical presentation, (K5 - K7) regarding the transmission route and (K7 - K9) regarding knowledge of self - protection, five questions on how to practice to avert the iatrogenic spread (P1 - P5) and seven questions on the attitude of dentist towards the treatment of the patient (A1 - A7). (Table no: 1 - 3) These questions were answered on a true / false basis. One point was given to a correct knowledge response and zero point was awarded to an incorrect response. The overall score for knowledge varied from 0 to 10 , with more points showing better knowledge regarding Covid19. Comparison of demographic details of respondents with mean knowledge, attitude and practice score was made by independent $\mathrm{t}$ - test and One-way ANOVA test. A P - value of less than 0.05 was considered statistically significant.

\section{Statistical Analysis}

The obtained data were transferred to the SPSS 13.01 software to draw the result. Independent $t$ test and One - way ANOVA test was used for intragroup and intergroup analysis. 


\section{RESULTS}

A total of 1560 participants completed the survey questionnaire. Among the final sample, $64.81 \%$ (1011) were women, and $35.2 \%$ (549) were men. While dividing the participants according to the working status, $20 \%$ of postgraduates were not working in any institution. Out of 80 $\%$ working postgraduate students, $21 \%$ postgraduates were of deemed colleges, $2.7 \%$ of government colleges, $56.4 \%$ of private colleges. Also, participants were categorised according to zones of India. The mean of total correct answers regarding knowledge given by male and female postgraduate students was $82.35 \%$. When comparing the association between gender of respondents with the level of knowledge, there was a statistically significant difference in males and females $(\mathrm{P}$ value $=0.0048$ ) according to an independent $\mathrm{t}$ - test. Association between gender of respondents and level of knowledge showed statistically significant difference, showing a high level of knowledge in $44.51 \%$ of female respondents and $38.80 \%$ of male respondents. When asked about interaction with a wild animal could cause Covid-19 (K5) and the measures taken to avoid Covid-19 infection were not obligatory for children and young adults (K9), there was a significant statistical difference between the responses of male and female respondents where the knowledge of females was higher regarding the same. But when asked about the spread of infection by infected individuals (K7), males showed higher knowledge with statistically significant values using the chi square test. But when asked questions related to the prevention of the spread of Covid-19 and attitude towards the treatment of patients, there was no statistical difference between male $(\mathrm{P}=0.3670)$ and female respondents $(\mathrm{P}=$ 0.6609). (Table 3)

Out of total postgraduate students, $20 \%$ of the students were not working in college in this pandemic outburst. When comparing responses of working postgraduate students in different universities with postgraduate students who were not working, results showed that the working postgraduate students had higher knowledge than nonworking students though, statistically insignificant using One-way ANOVA test. Overall government college's postgraduate students showed higher knowledge when compared with PG's working in other healthcare sectors and the PG's who were not working in the colleges. Also, when asked about the modes of transmission of infection, (K5, K6) $100 \%$ correct responses were given from students working in government colleges. In case of questions regarding the main clinical symptom for Covid-19, postgraduate students of deemed colleges have given the right answers showing a statistically significant value using the chi - square test. Also, there was statistically significant difference in result when we compared to different health sectors with measures taken to prevent the spread of infection and attitude towards the treatment of the patient. Using Tukey's multiple post hoc procedures, there was a statistically significant intragroup difference between government and deemed college students $(\mathrm{P}=0.05)$ when asked regarding measures taken to prevent the spread of infection. Also, a significant was seen when compared between deemed vs nonworking $(\mathrm{P}=$ $0.03)$ and students working in private colleges $(p=0.03)$. (Table 4)

Majority of the responses were from western (48.3\%) and southern zone (41\%) across India whereas northern zone accounted for $5 \%$, central zone $3.3 \%$ and least i.e. $2.5 \%$ formed eastern zone. While comparing the respondents working in different zones of India with the correct knowledge, the central zone $(P=0.0001)$ of India showed a high level of knowledge with statistically significant results using One-way ANOVA test. In case of questions regarding clinical presentation and modes of transmission (K1, K6, K8), the central zone accounted higher knowledge score with statistically significant results. Eastern zone postgraduate students showed $100 \%$ correct knowledge about clinical presentation and $(\mathrm{K} 1, \mathrm{~K} 3)$ and transmission route (K9) of the disease with statistically significant values. Northern zone respondents showed a statistically significant result on the questions concerning symptomatic and supportive treatment that could help the patients of Covid-19 (K3) when compared with another zone. Also, when asked about the main clinical symptoms of Covid-19 (K1), responses showed a statistically significant difference between different zones, with central and eastern zone showing the highest score with a statistically significant difference using the chi-square test. Also, there was no statistically significant result when compared to different zones with measures to prevent the spread of infection and attitude towards the treatment of patients. (Table 5)

Most participants agreed that taking precautions such as practising proper hand hygiene (98.27\%), disinfecting the contact surface (96.92), wearing PPE (94.04), isolation of cases (94.42) can prevent the spread of disease (P1 - P5). In case of questions concerning the role of dentists in Covid-19 pandemic (P5), $98.85 \%$ of participants agreed that dentists had a role in increasing the awareness and educating people. Participants were asked seven questions for assessing the attitude towards the treatment of patients. Total of $99.81 \%$ population agreed that proper medical and travel history was a must before consulting the patient (A1). $81.73 \%$ participants agreed that if patients were continuously coughing or sneezing, they should be referred to flu clinic for testing whereas $13.46 \%$ disagrees with the statement and $4.81 \%$ participants opted for I don't know option (A2). 95.96 $\%$ of participants agreed that if the dental personnel had flu like symptoms, they should not be allowed to work on the patients (A3).

\begin{tabular}{|c|c|c|}
\hline Knowledge Questionnaire to Understand the Awareness about Novel Coronavirus & Correct \% & Incorrect \% \\
\hline K1. COVID-19's principal clinical symptoms are fever, tiredness, dry cough, and myalgia. & 97.31 & 2.69 \\
\hline K2. Common cold, runny nose, stuffy nose and sneezing are less common in people with COVID-19 virus infections. & 52.12 & 47.88 \\
\hline K3. COVID - 2019 currently does not have an effective cure, but symptomatic and supportive care can aid many patients & 98.65 & 1.35 \\
\hline $\begin{array}{l}\text { K4. Not all patients will advance to critical stage with COVID - 2019. Only those who are aged, suffering from chronic diseases and } \\
\text { overweight has higher incidence. }\end{array}$ & 85.19 & 14.81 \\
\hline K5. Interactions with wild animals will lead to COVID-19 virus infection. & 84.81 & 15.19 \\
\hline K6. When there is no fever, individuals with COVID - 2019 cannot infect others with the viral infection. & 93.27 & 6.73 \\
\hline K7. This virus (COVID-19) is spread by infected individuals through airborne droplets. & 94.42 & 5.58 \\
\hline K8. General medical masks can be used by ordinary residents for preventing COVID-19 infection. & 27.31 & 72.69 \\
\hline K9. Measures to avoid COVID-19 infection are not obligatory for children and young adults. & 93.27 & 6.73 \\
\hline \multicolumn{3}{|l|}{ Table 1. Responses for Knowledge Questionnaire from Respondents } \\
\hline
\end{tabular}




\begin{tabular}{|c|c|c|c|}
\hline Practice and Attitude Related Questionnaire to Assess Iatrogenic Spread of Infection & Agree \% & Disagree $\%$ & I don't know \% \\
\hline P1. Does cleaning hand by using hand rub or soap based on alcohol can prevent the spread of infection? & 98.27 & 1.35 & 0.38 \\
\hline $\begin{array}{l}\text { P2. Does cleaning and disinfecting the surface in contact with known or suspect patients routinely can prevent } \\
\text { infection from spreading? }\end{array}$ & 96.92 & 1.35 & 1.73 \\
\hline P3. Could PPE like mask, dental goggle, and gloves prevent the spread of infection? & 94.04 & 4.23 & 1.73 \\
\hline P4. Can isolation of known or suspected patients in suitably ventilated single rooms prevent spread? & 94.42 & 2.88 & 2.69 \\
\hline P5. Does dentist have a role to play in educating the public and increasing awareness about COVID-19 infection. & 98.85 & 0.38 & 0.77 \\
\hline A1. By taking proper medical or travel history before consulting the patient. & 99.81 & 0.19 & 0.00 \\
\hline A2. Patients coughing or sneezing should be referred to the hospital without treatment. & 81.73 & 13.46 & 4.81 \\
\hline A3. Dental personnel with flu - like symptoms should not be permitted to work with the patient. & 95.96 & 3.65 & 0.38 \\
\hline A4. Before and after use, case paper should be sprayed with the disinfecting solution & 93.65 & 3.65 & 2.69 \\
\hline A5. Dentist should postpone appointment if there is no urgent need for treatment. & 98.65 & 0.96 & 0.38 \\
\hline A6. Dentists should use their personal protective kit while conversing with patients. & 85.96 & 11.73 & 2.31 \\
\hline A7. For consultation or treatment cashless payment option should be preferred & 98.08 & 1.54 & 0.38 \\
\hline \multicolumn{4}{|c|}{ Table 2. Responses for Practice and Attitude Questionnaire from Respondents } \\
\hline
\end{tabular}

\begin{tabular}{|c|c|c|c|c|c|c|}
\hline \multirow{2}{*}{ Variables } & \multicolumn{2}{|c|}{ Male } & \multicolumn{2}{|c|}{ Female } & \multirow{2}{*}{ t - Value } & \multirow{2}{*}{ P - Value } \\
\hline & Mean & SD & Mean & SD & & \\
\hline Knowledge & 8.17 & 1.01 & 8.31 & 0.95 & -2.8231 & $0.0048^{*}$ \\
\hline Practice & 11.75 & 0.75 & 11.72 & 0.85 & 0.9023 & 0.3670 \\
\hline Attitude & 13.42 & 0.84 & 13.44 & 0.93 & -0.4388 & 0.6609 \\
\hline
\end{tabular}

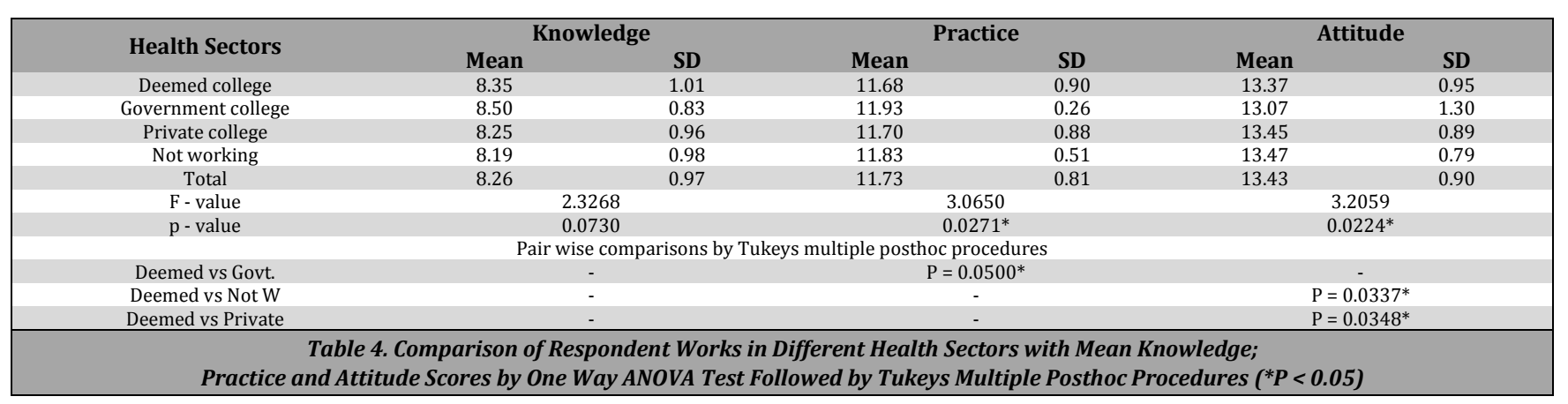

\begin{tabular}{|c|c|c|c|c|c|c|}
\hline \multirow{2}{*}{ Zones } & \multicolumn{2}{|c|}{ Knowledge } & \multicolumn{2}{|c|}{ Practice } & \multicolumn{2}{|c|}{ Attitude } \\
\hline & Mean & SD & Mean & SD & Mean & Sd \\
\hline Central zone & 8.47 & 1.05 & 11.59 & 1.04 & 13.59 & 0.70 \\
\hline Eastern zone & 7.92 & 0.84 & 12.00 & 0.00 & 13.54 & 0.85 \\
\hline Nor then zone & 8.19 & 1.15 & 11.81 & 0.56 & 13.46 & 0.64 \\
\hline Southern zone & 8.14 & 0.95 & 11.74 & 0.86 & 13.45 & 0.90 \\
\hline Western zone & 8.38 & 0.95 & 11.71 & 0.80 & 13.39 & 0.93 \\
\hline Total & 8.26 & 0.97 & 11.73 & 0.81 & 13.43 & 0.90 \\
\hline F - value & \multicolumn{2}{|c|}{7.5682} & \multicolumn{2}{|c|}{1.7730} & \multicolumn{2}{|c|}{0.9069} \\
\hline $\mathrm{P}$ - value & \multicolumn{2}{|c|}{$0.0001^{*}$} & \multicolumn{2}{|c|}{0.1317} & \multicolumn{2}{|c|}{0.4590} \\
\hline \multicolumn{7}{|c|}{ Pair wise comparisons by Tukeys multiple posthoc procedures } \\
\hline Central vs Eastern & \multicolumn{2}{|c|}{$P=0.0500^{*}$} & \multicolumn{2}{|c|}{ - } & \multicolumn{2}{|c|}{ - } \\
\hline Eastern vs Western & \multicolumn{2}{|c|}{$\mathrm{P}=0.0304^{*}$} & \multicolumn{2}{|c|}{ - } & \multicolumn{2}{|c|}{-} \\
\hline Southern vs Western & \multicolumn{2}{|c|}{$\mathrm{P}=0.0001^{*}$} & \multicolumn{2}{|c|}{-} & \multicolumn{2}{|c|}{-} \\
\hline Practice a & $\begin{array}{l}\text { mparis } \\
\text { es by }\end{array}$ & $\begin{array}{l}\text { ndent } \\
\text { VA T }\end{array}$ & $\begin{array}{l}\text { fferent } \\
\text { by Tuke }\end{array}$ & $\begin{array}{l}\text { Iean I } \\
\text { Post I }\end{array}$ & $1 * D$ & \\
\hline
\end{tabular}

\section{DISCUSSION}

In case of questions regarding disinfection of case sheet, 93.65 $\%$ participants agreed that the case sheet should be disinfected before and after use (A4). $98.95 \%$ of participants agreed that if the need of treatment was not urgent, treatment should be postponed (A5). While conversing with patients, $85.96 \%$ of participants agreed that dentists should wear PPE kit whereas $11.73 \%$ population disagreed with the statement. Most of the participants preferred the option of cashless payment for consultation or treatment (A7).

To the best of our knowledge, this is the first study in India to assess the knowledge, measures of prevention taken by dentists, and attitude towards the treatment of patients in Covid-19 pandemic among Indian dental postgraduate students. This period is considered as one of the difficult periods for the health sector workers and has many challenges and tension, but there are obligations and duties of doctors toward patients, society, and members of their families. To help healthcare workers WHO is working closely with leading experts, governments and partners to rapidly expand scientific information on this new virus and to provide timely advice on steps to protect human health and prevent the spread of this pandemic.

We examined the characteristics of awareness, prevention and attitude towards Covid-19 and identified some demographic variables correlated with knowledge, attitude and practice; these results are helpful to public health decision makers and health professionals in identifying target groups for Covid-19 health and prevention and education with respect to different zones of India. In this study, predominantly females, students working in government dental colleges and respondents residing in the central zone of India showed a higher level of knowledge. Although we found statistically significant differences in results only when comparing gender with knowledge questionnaire.

The finding of a correct high rate of Covid-19 knowledge in Indian dental postgraduates was expected because this epidemiological survey was conducted during the late lockdown 3.0 phase in India. Still, results showed that more than $50 \%$ of the population was having a low level of 
knowledge. Because of the problematic situation of the epidemic and the overwhelming news reports on this public health emergency, this population should actively learn about this infectious disease or have sufficiently good knowledge

Attitudes towards Covid-19 were optimistic; most postgraduates took precautions to prevent infection of Covid19 by using PPE, isolation from known or suspected patients, regular cleaning of hands by using hand rub. Also, they took adequate precautions by avoiding going to busy areas, including train stations, and discouraging public transport. Such rigid protective policies may be attributed largely to the very stringent preventive and regulatory measures introduced by municipal governments such as the prohibition of public meetings and social gatherings. Unfortunately, when asked about do dentists have a role to play in educating the public, and increasing awareness about Covid-19 infection, $0.4 \%$ of postgraduates denied the statement whereas $0.8 \%$ postgraduates selected I don't know option.

According to WHO guidelines, doctors should understand and follow the instructions on adequate infection prevention and control (IPC) and get well trained for using personal protective equipment's (PPE). ${ }^{11}$ Healthcare workers who deal with suspected or confirmed Covid-19 cases should be given clear instructions on the use of medical face masks, protective eye glasses, gloves and a waterproof dress, before starting any procedure. ${ }^{12} \mathrm{~A}$ hand hygiene practice should be carried out before and after commencement of any procedure and surface in contact with known or suspected patient should be cleaned with disinfecting solution and a regular fumigation should be carried out. ${ }^{13}$

This survey shows the levels of knowledge, attitudes and practices on Covid-19 among the participants which will be helpful in designing effective educational programmes. The current survey, in fact, exposes the need for more comprehensive education programmes with focus on consistency of information from WHO, Dental council of India (DCI) and related authorities.

\section{CONCLUSIONS}

The dental postgraduate students will be gearing up to complete the clinical work soon, but unfortunately, they did not have sufficient knowledge regarding the critical situation. By pursuing educational courses and updates regarding Coronavirus 19, they can improve the standard of selfprotection and treatment. Training to treat patients should be structured according to various demographic conditions, and management processes of hospitals should ensure that frontline staff have adequate time to relax during corona pandemic to prevent overwork and involuntary mistakes.

Data sharing statement provided by the authors is available with the full text of this article at jemds.com.

Financial or other competing interests: None.

Disclosure forms provided by the authors are available with the full text of this article at jemds.com.

\section{REFERENCES}

[1] Harapan H, Itoh N, Yufika A, et al. Coronavirus disease 2019 (COVID-19): a literature review. J Infect Public Health 2020;13(5):667-73.

[2] Zhong BL, Luo W, Li HM, et al. Knowledge, attitudes and practices towards COVID-19 among Chinese residents during the rapid rise period of the COVID-19 outbreak: a quick online cross-sectional survey. Int J Biol Sci 2020;16(10):1745-52.

[3] Khader Y, Al Nsour M, Al-Batayneh OB, et al. Dentists' awareness, perception and attitude regarding COVID-19 and infection control: cross-sectional study among Jordanian dentists. JMIR Public Health Surveill 2020;6(2):e18798.

[4] Ahmed MA, Jouhar R, Ahmed N, et al. Fear and practice modifications among dentists to combat Novel Coronavirus Disease (COVID-19) outbreak. Int J Environ Res Public Health 2020;17(8):2821.

[5] Arti MK, Bhatnagar K. Modeling and predictions for COVID-19 spread in India. Research Gate 2020. [Accessed 02 ${ }^{\text {nd }}$ May 2020] URL: https://www.researchgate.net/publication/340362418_ Modeling_and_Predictions_for_COVID_19_Spread_in_Indi a/citations

[6] Ather A, Patel B, Ruparel NB, et al. Coronavirus disease 19 (COVID-19): implications for clinical dental care. J Endod 2020;46(5):584-95.

[7] Sohrabi C, Alsafi Z, O'Neill N, et al. World Health Organization declares global emergency: a review of the 2019 novel coronavirus (COVID-19). Int J Surg 2020;76:71-6

[8] Chatterjee P, Nagi N, Agarwal A, et al. The 2019 novel coronavirus disease (COVID-19) pandemic: a review of the current evidence. Indian J Med Res 2020;151(2\&3):147-59.

[9] Bhagavathula AS, Aldhaleei WA, Rahmani J, et al. Novel coronavirus (COVID-19) knowledge and perceptions: a survey on healthcare workers. MedRxiv 2020. [Accessed 29th May 2020] URL: https://www.medrxiv.org/content/10.1101/2020.03.09 $.20033381 v 2$

[10] Izzetti R, Nisi M, Gabriele M, et al. COVID-19 transmission in dental practice: brief review of preventive measures in Italy. J Dent Res 2020;99(9):1030-8.

[11] De Lusignan S, Bates C, Bernal JL, et al. The oxford royal college of general practitioners clinical informatics digital hub: protocol to develop extended COVID-19 surveillance and trial platforms. JMIR Public Health Surveill 2020;6(3):e19773.

[12] Adhikari SP, Meng S, Wu YJ, et al. Epidemiology, causes, clinical manifestation and diagnosis, prevention and control of coronavirus disease (COVID-19) during the early outbreak period: a scoping review. Infect Dis Poverty 2020;9(1):29.

[13] Wałaszek M, Kołpa M, Różańska A, et al. Hospital knowledge and practice of doctors and nurses regarding hand hygiene in a survey. Przegl Epidemiol 2020;74(1):119-32. 